\title{
An Audit into the Nature of Operations of Agro-processing Micro, Small and Medium Enterprises (MSMEs) in Uganda
}

\author{
Julia Kigozi (Corresponding author) \\ Department of Agricultural \& Bio-systems Engineering, Makerere University \\ P. O. Box 7062, Kampala, Uganda \\ Tel: +256772609649Ｅ-mail: jbulyakigozi@yahoo.com

\begin{abstract}
Emmanuel Baidhe
Department of Agricultural \& Bio-systems Engineering, Makerere University

P. O. Box 7062, Kampala, Uganda
\end{abstract}

Ivan Muzira Mukisa

Department of Food Technology and Nutrition, Makerere University

P. O. Box 7062, Kampala, Uganda

\begin{abstract}
Charles Muyanja
Department of Food Technology and Nutrition, Makerere University

P. O. Box 7062, Kampala, Uganda
\end{abstract}

Leatitiah Namubiru

Uganda National Bureau of Standards (UNBS)

P. O. Box 6329, Kampala, Uganda

Brenda Katarikawe

Uganda Export Promotion Board (UEPB)

P. O. Box 5045, Kampala, Uganda 
Received: June 21, 2021 Accepted: July 29, 2021 Published: December 30, 2021

doi:10.5296/jfi.v5i1.19372

URL: http://dx.doi.org/10.5296/jfi.v5i1.19372

\begin{abstract}
The agro-processing Micro, Small, and Medium-Sized Enterprises (MSMEs) form an integral part of the manufacturing sector in Uganda. To effectively facilitate product certification among MSMEs, there is a need to fully understand the nature of their operations so that appropriate interventions can be put in place. This study assessed the status quo of operations at selected MSMEs in Uganda. A semi-structured paper-based questionnaire was administered to the owners, managers, or supervisors of 40 selected agro-processing MSMEs enrolled under the project "Empowerment of the Agro-Processing Industry to meet the Quantity and Quality Standards for the Local and Export Market", a programme enhancing the practical skills of students at Makerere University dubbed the "EAPI Project." The seven-section questionnaire consisted of both quantitative and qualitative questions focusing on (i) product optimization, (ii) raw material verification and storage, (iii) good manufacturing practices, (iv) measuring and testing equipment, (v) product assessment, presentation, and storage, (vi) waste and pest management, and (vii) infrastructure and energy utilization. The results indicated that only $23.7 \%$ of agro-processing MSMEs clearly understood the standards. Packaging was the most optimized parameter (74.4\%), followed by texture and sensory properties (59\% and 51.1\%, respectively). About $74 \%$ of the agro-processing MSMEs were compliant in declaring the raw materials on the product label. Maintenance of valid medical certificates, routine inspection of personnel, and provision of protective gear ranked low, with a score of 1 out of 10 . Inadequate documentation was a cross-cutting issue for all operations, yet it was a driver for GMPs. There is a need to strengthen the understanding and practice of food processing standards from the Uganda National Bureau of Standards (UNBS), in the agro-processing MSMEs through continuous human and institutional-capacity development programs.
\end{abstract}

Keywords: Agro-processing, Micro, Small, Medium Scale Enterprises (MSMEs), Good Manufacturing Practices (GMPs), Product certification, Uganda

\title{
1. Introduction
}

Globally, Micro, Small, and Medium-Enterprises (MSMEs) are recognized for their catalytic contribution to sustainable development through job creation and poverty alleviation (Abisuga-Oyekunle et al., 2019; Gherghina et al., 2020; Kakembo et al., 2021; Shafi et al., 2020). MSMEs account for two-thirds of global employment and between 80 and $90 \%$ of employment in low-income countries. It is estimated that over $95 \%$ of enterprises across the world are small and medium-enterprises (SMEs) (Quartey et al., 2017). The increased establishment of MSMEs is attributable to the flexibility in production opportunities compared to the large-scale enterprises. MSMEs quickly adapt to changes in demand and easily become competitive (Erdin \& Ozkaya, 2020). 


\section{Macrothink}

In Uganda, the MSME sector accounts for nearly $90 \%$ of the entire private sector (Lakuma et al., 2019), over $80 \%$ of manufactured output, and about $75 \%$ to the gross domestic product (GDP) (Hamiza, 2020; MTIC, 2015). MSMEs contribute substantially to the provision of basic goods and services and the generation of export and tax revenue for national socio-economic development and, therefore, require focus in a nation's development agenda. Despite their role in the country's development, MSMEs in Uganda still face challenges including limited access to finances, inadequate technical and business skills, limited access to appropriate technologies, limited access to quality assurance and affordable certification process, and limited access to markets (MTIC, 2015). Therefore, action is required to enhance their capacity to compete in domestic, regional, and international markets so as to enhance Uganda's industrialization agenda.

As part of the efforts to boost market penetration for Ugandan products, the government of Uganda, through the Uganda National Bureau of Standards (UNBS), set up regulations that require all products covered by compulsory standards to be certified with the UNBS Distinctive Mark (Q-Mark) (UNBS, 2018). Food-related products such as juices, beverages, and confectioneries produced by the agro-processing MSMEs are part of the products affected by the above regulation.

To foster compliance among MSMEs, certification fees were lowered to amounts that are relatively affordable for MSMEs. Currently, permit fees for product certification for MSMEs stand at UGX 350,000 (100 USD) compared to UGX 800,000 (220 USD) for large scale companies (UNBS, 2019). Notwithstanding the efforts by UNBS to have more products certified, many of the agro-processing MSMEs continue to operate without product certification. To effectively facilitate product certification among agro-processing MSMEs, there is need to fully understand the nature of operations at the MSMEs so that appropriate interventions can be put in place. This study assessed the operational status quo at selected MSMEs in Uganda.

\section{Methodology}

\subsection{Study Population}

The study population comprised of agro-processing MSMEs within Kampala Metropolitan Area (KMA) and the neighboring districts such as Kayunga, Mityana, Kasanda, and Luwero enrolled under the EAPI Project (Empowerment of the Agro-Processing Industry (EAPI) to meet the Quantity and Quality Standards for the Local and Export Market; a programme enhancing the practical skills of students in Makerere University). Majority of the MSMEs are largely concentrated in the major urban areas of Uganda (Hamiza, 2020) with the majority in Kampala district.

A total of 40 agro-processing MSMEs were purposively recruited from groups of processors registered under UNBS, Uganda Small Scale Industries Association (USSIA) and Food Technology Business Incubation Centre (FTBIC) at Makerere University. UNBS offers regulatory function for product certification in Uganda and therefore maintains a record of all processing industries regardless of the product certification status. USSIA is a not-for-profit 


\section{MInstitute Macrothink $_{\text {Int }}$}

business association of Micro, Small and Medium Industries (MSMI) in Uganda. USSIA supports and equips small and medium-sized enterprises especially the small-scale industrial sector of Uganda for success and economic growth. FTBIC offers incubation space for several start-ups from ideation to product development. All participating agro-processing MSMEs were those using agricultural produce as raw material for product development. Only 39 agro-processing MSMEs were available for interviews during the survey.

\subsection{Overview of the EAPI Project}

The EAPI Project offers free consulting services to agro-processing MSMEs. The project aims at strengthening product quality, production processes, infrastructure, and marketing strategies of agro-processing MSMEs in Uganda using the Agro-Processing Pro Model. The Agro-Processing Pro Model is based on the Triple Helix Model, which defines the need and importance of a partnership between Government, private sector, and academia to impact the private sector. The project uses a wholesome approach in its methodology that enables agro-processors to receive knowledge, and mentorship in practical skills leading to product certification by UNBS.

\subsection{Data Collection}

A survey was conducted at all the 39 facilities to provide current information to cover all the key strategic areas that complement the process of acquiring the UNBS certification mark $(\mathrm{Q}$ - mark). Data was collected using a semi-structured paper-based questionnaire. The confidentiality of the information obtained from participants was assured with a signed consent and confidentiality clause. The questionnaire comprised of seven sections (appendix). Section 1 focused on product optimization particularly in relation to product standards. The MSME's "own" analysis of four parameters, including physical product texture, sensory acceptability, nutritional properties, and packaging, was used to assess the extent to which product optimization was carried out by the MSME. In section 2, the respondents were asked about raw material verification and storage. Section 3 focused on aspects of good manufacturing practices, including cleaning of both equipment and premises, medical certificates, protective gear, toilet facilities, and personnel hygienic inspection. The quality of personnel hygiene was measured on a scale 0-10 considering parameters related with personal hygiene including maintenance of valid medical certificates, routine inspection of personnel, provision of protective gears. provision and maintenance of toilet facilities. Section 4 emphasized matters of measuring and testing equipment at the facilities. Product assessment, presentation and storage were handled in section 5. In section 6 , the respondents were asked about their waste and pest management strategies. Infrastructure and energy utilization were covered as part of section 7. The greatest part of the questionnaire consisted of quantitative questions. Qualitative questions were included at some points to help capture details that help understand the quantitative data. The interviews were conducted with one participant per MSMEs. Only decision-making participants such as owners or proprietors, managers, or supervisors were involved in the interview at the respective agro-processing MSMEs. 


\section{Macrothink}

\subsection{Data Analysis}

The collected data was entered into a data base and organized by category. Quantitative data was processed, analyzed and organized in tables using Microsoft Excel 2019. Descriptive statistical values including frequencies, percentages, maximum, minimum, and average values were used to explain the distribution.

\section{Results and Discussion}

\subsection{Product optimization}

\subsubsection{MSMEs' use of UNBS standards for product optimization}

The survey revealed that out of all the agro-processors, only $28 \%$ of the participating agro-processing facilities had the pre-requite standards for their products and operations. The facilities mainly had US 28 EAS 39:2002 - Code of practice for hygiene in the drink and food manufacturing industry, and US EAS 38: 2014 - Labelling of pre-packaged foods. It was also found that only $23.7 \%$ clearly understood the standards as summarized in Table 1.

Table 1. Personnel's understanding of UNBS standards at the MSME

\begin{tabular}{llll}
\hline Level of Understanding & Freq. & Percent & Valid proportion \\
\hline Not at all & 15 & $38.5 \%$ & $39.5 \%$ \\
Slightly understood & 6 & $15.4 \%$ & $15.8 \%$ \\
Understood & 8 & $20.5 \%$ & $21.1 \%$ \\
Very clearly understood & 9 & $23.1 \%$ & $23.7 \%$ \\
Total & 38 & $97.5 \%$ & $100 \%$ \\
Missing & 1 & $2.6 \%$ & \\
Total & 39 & $100.0 \%$ & \\
\hline
\end{tabular}

\subsubsection{Product Optimization in MSMEs}

Results indicated that majority $(27.8 \%)$ had at least three parameters optimized as shown in Table 2. Packaging was the most optimized parameter $(74.4 \%)$, followed by texture and sensory properties with $59 \%$ and $51.1 \%$, respectively, as shown in Table 3 . 
Table 2. Extent of product optimization

\begin{tabular}{llll}
\hline Number of parameters optimized & Freq. & Percent & Valid Proportion \\
\hline No parameter optimized & 2 & $5.1 \%$ & $5.6 \%$ \\
One aspect optimized & 7 & $17.9 \%$ & $19.4 \%$ \\
Two aspects optimized & 8 & $20.5 \%$ & $22.2 \%$ \\
Three aspects optimized & 10 & $25.6 \%$ & $27.8 \%$ \\
All aspects optimized & 9 & $23.1 \%$ & $25.0 \%$ \\
Total & 36 & $92.2 \%$ & $100 \%$ \\
Missing & 3 & $7.7 \%$ & \\
Total & 39 & $100.0 \%$ & \\
\hline
\end{tabular}

Table 3. Types of parameters that agro-processing MSMEs optimize

\begin{tabular}{llll}
\hline Parameter optimized & Freq. & Percent & Valid proportion \\
\hline Textural & 23 & $25.8 \%$ & $59.0 \%$ \\
Sensory & 20 & $22.5 \%$ & $51.3 \%$ \\
Nutrition & 17 & $19.1 \%$ & $43.6 \%$ \\
Packaging & 29 & $32.6 \%$ & $74.4 \%$ \\
Total & 89 & $100.0 \%$ & $100 \%$ \\
\hline
\end{tabular}

\subsection{Raw Material Verification and Storage}

With regards to declaring raw materials on product labels, $74 \%$ of the agro-processing MSMEs were compliant while $25.6 \%$ partially declare the raw materials on the product label. Generally, over $50 \%$ of the agro-processing MSMEs do not adequately maintain records for the incoming raw materials (Table 4). The results indicate that $26.3 \%$ of the respondents have never made any records for the incoming raw material. The suitability of the raw material storage at the facilities scored equally for slightly suitable but with several gaps, moderately suitable with few gaps, and suitable at $25 \%$ (Table 5). Only $5.6 \%$ of the agro-processing MSMEs had very suitable storage areas for the raw materials. 
Table 4. Maintenance of raw material Rrcords at agro-processing MSMEs

\begin{tabular}{llll}
\hline Frequency of Record maintenance & Freq. & Percent & Valid proportion \\
\hline Never & 10 & $25.6 \%$ & $26.3 \%$ \\
Once in a while & 9 & $23.1 \%$ & $23.7 \%$ \\
Twice a week & 3 & $7.7 \%$ & $7.9 \%$ \\
Thrice a week & 1 & $2.6 \%$ & $2.6 \%$ \\
Always maintained & 15 & $38.5 \%$ & $39.5 \%$ \\
Total & 38 & 97.5 & $100 \%$ \\
Missing & 1 & $2.6 \%$ & \\
Total & 39 & $100.0 \%$ & \\
\hline
\end{tabular}

Table 5. Raw material storage at the agro-processing MSMEs

\begin{tabular}{llll}
\hline Suitability of Raw material storage & Freq. & Percent & Valid Proportion \\
\hline Not suitable at all & 7 & $17.9 \%$ & $19.4 \%$ \\
Slightly suitable with several gaps & 9 & $23.1 \%$ & $25.0 \%$ \\
Moderately suitable with few gaps & 9 & $23.1 \%$ & $25.0 \%$ \\
Suitable & 9 & $23.1 \%$ & $25.0 \%$ \\
Very suitable & 2 & $5.1 \%$ & $5.6 \%$ \\
Total & 36 & $92.3 \%$ & $100 \%$ \\
Missing & 3 & $7.7 \%$ & \\
Total & 39 & $100.0 \%$ & \\
\hline
\end{tabular}

\subsection{Good Manufacturing Practices (GMPs)}

\subsubsection{Cleanliness of Processing Facilities}

Only a handful of the agro-processing MSMEs (17.9\%) had well documented cleaning plans, although $61.5 \%$ had clearly identified cleaning materials such as mops, brushes, liquid soap, buckets. On a scale of $0-10$, most facilities ranked at 1 out of 10 indicating that they did not have well established routines for cleaning equipment and premises (Figure 1). Majority of the facilities maintained their floors, walls, and ceilings clean as shown in Figure 1. 


\section{Macrothink}

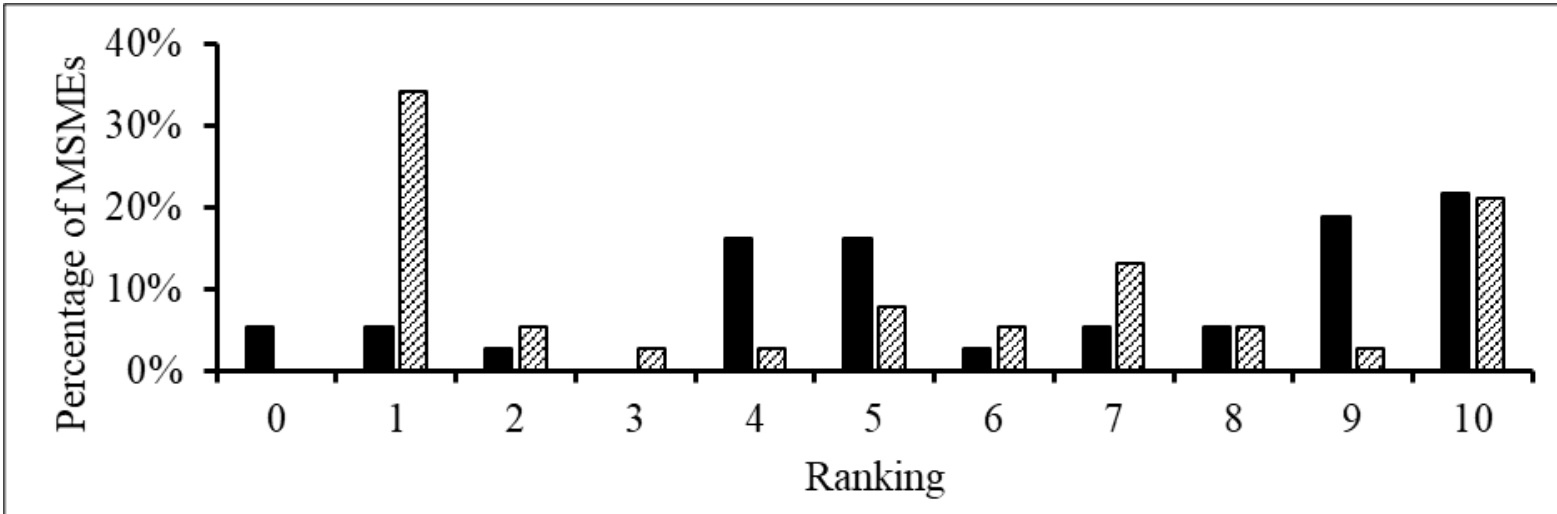

Floors, wall, \& ceilings maintained clean

Established routine for cleaning equipment \& premises

Figure 1. Proportion of agro-processing MSMEs (i) Where floor, walls, and ceilings are maintained clean (ii) Have established routine for cleaning equipment and premises

\subsubsection{Personnel Hygiene}

Results indicated that maintenance of valid medical certificates, routine inspection of personnel, provision of protective gears ranked low with a score 1 out 10 . Provision and maintenance of toilet facilities ranked fairly well as $30.6 \%$ of the facilities had a rank of 10 (Figure 2). Also, 56.4\% of the agro-processing MSMEs had adequate hand washing facilities.

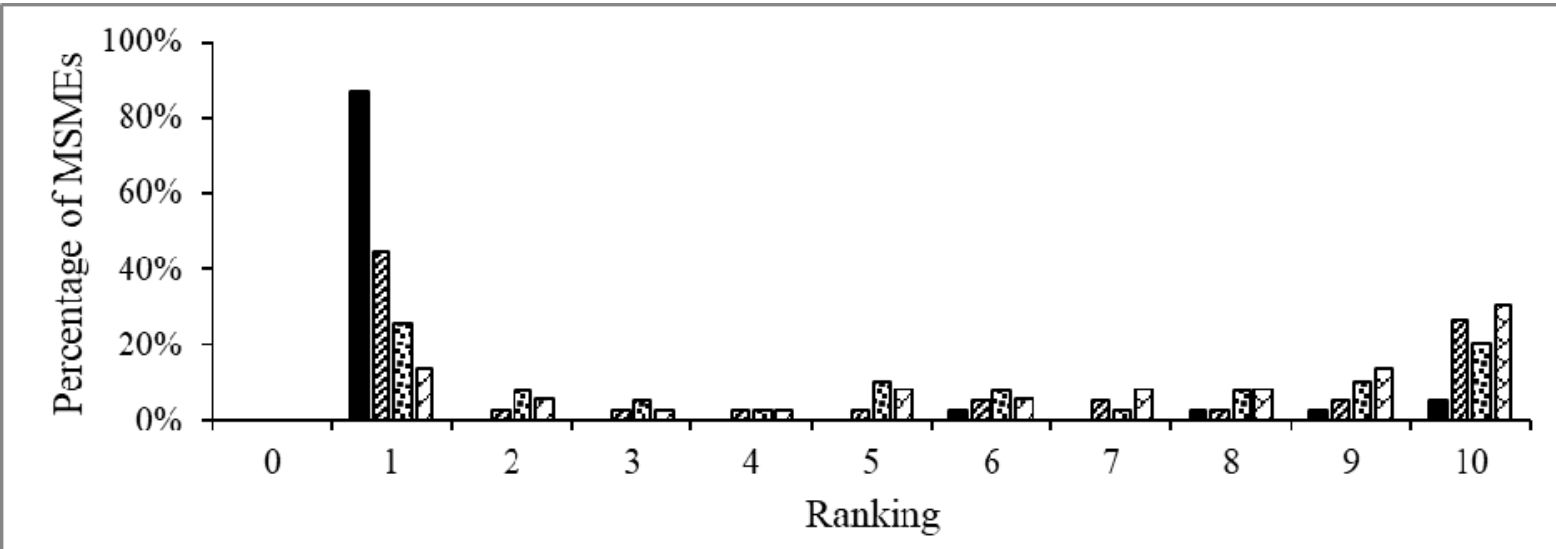

- Valid medical certificates maintained $\boldsymbol{Q}$ Personnel routinely inspected 由 Appropriate protective gear provided $\square$ Toilet facilities provided \& maintained

Figure 2. Ranking of some of the parameters related to personal hygiene 


\subsubsection{Production Process Controls}

Of all the agro-processing MSMEs that participated in the survey, 64.1\% were not in operation on the day of the audit. The results also established that only $7.7 \%$ of the agro-processing MSMEs had very clear production process controls, 30.8\% had clear production process controls but with a lot of gaps and $28.2 \%$ had completely no clear production process controls (Table 6). The survey further revealed that $66.7 \%$ of the participating agro-processing MSMEs had never prepared records for the production process controls as shown in Table 7.

Table 6. Possession of clear production process controls at MSMEs

\begin{tabular}{llll}
\hline Frequency of Maintaining Records & Freq. & Percent & Valid proportion \\
\hline None & 11 & $28.2 \%$ & $28.2 \%$ \\
Yes, with a lot of gaps & 12 & $30.8 \%$ & $30.8 \%$ \\
Yes with a few gaps & 5 & $12.8 \%$ & $12.8 \%$ \\
Yes, with slightly clear process control & 8 & $20.5 \%$ & $20.5 \%$ \\
Yes, with very clear process controls & 2 & $7.7 \%$ & $7.7 \%$ \\
Total & 39 & $100 \%$ & $100 \%$ \\
Missing & 0 & 0.0 & \\
Total & 39 & $100.0 \%$ & \\
\hline
\end{tabular}

Table 7. Maintaining records for production process controls at MSMEs

\begin{tabular}{llll}
\hline Frequency of Maintaining Records & Freq. & Percent & Valid proportion \\
\hline Never & 26 & $66.7 \%$ & $66.7 \%$ \\
Once in a while & 3 & $7.7 \%$ & $7.7 \%$ \\
Twice a week & 2 & $5.1 \%$ & $5.1 \%$ \\
Thrice a week & 0 & $0.0 \%$ & $0.0 \%$ \\
Always maintained & 8 & $20.5 \%$ & $20.5 \%$ \\
Total & 39 & $100 \%$ & $100 \%$ \\
Missing & 0 & $0.0 \%$ & \\
Total & 39 & $100.0 \%$ & \\
\hline
\end{tabular}




\section{Macrothink \\ Journal of Food Industry \\ ISSN 1948-545X 2021, Vol. 5, No. 1}

\subsection{Measuring and Testing equipment}

Findings indicate that most of the agro-processing MSMEs (42.1\%) lacked appropriate equipment to facilitate production. About $31.6 \%$ of the agro-processing MSMEs neither had adequate nor calibrated their measuring equipment (Table 8). Some of the instruments possessed by the processors include weighing scales, thermometers, alcoholmeters, and refractometers. For agro-processing MSMEs whose instruments were calibrated, calibration was done either by UNBS or individually at the facility using the manufacturers' guidance.

Table 8. Possession and calibration of measuring and testing equipment at MSMEs

\begin{tabular}{llll}
\hline Adequate possession and calibration of equipment & Freq. & Percent & Valid proportion \\
\hline None & 16 & $41.0 \%$ & $42.1 \%$ \\
Neither adequate nor calibrated & 12 & $30.8 \%$ & $31.6 \%$ \\
Adequate and calibrated & 10 & $25.6 \%$ & $26.3 \%$ \\
Total & 38 & $97.4 \%$ & $100 \%$ \\
Missing & 1 & $2.6 \%$ & \\
Total & 39 & $100.0 \%$ & \\
\hline
\end{tabular}

\subsection{Product assessment, presentation, and storage}

Generally, the greatest proportion of agro-processing MSMEs ranked poorly on a scale of 10 for adequacy of the product assessment protocols as shown in Figure 3. The survey results further indicated that non-conforming products in most of the agro-processing MSMEs are not properly identified and separated as shown in Figure 5. Only a handful of processors that identified non-conforming products either recycled the product to better it for the market, discarded it or sold it at a much lower price. Very few processors had a register for non-conforming products. 


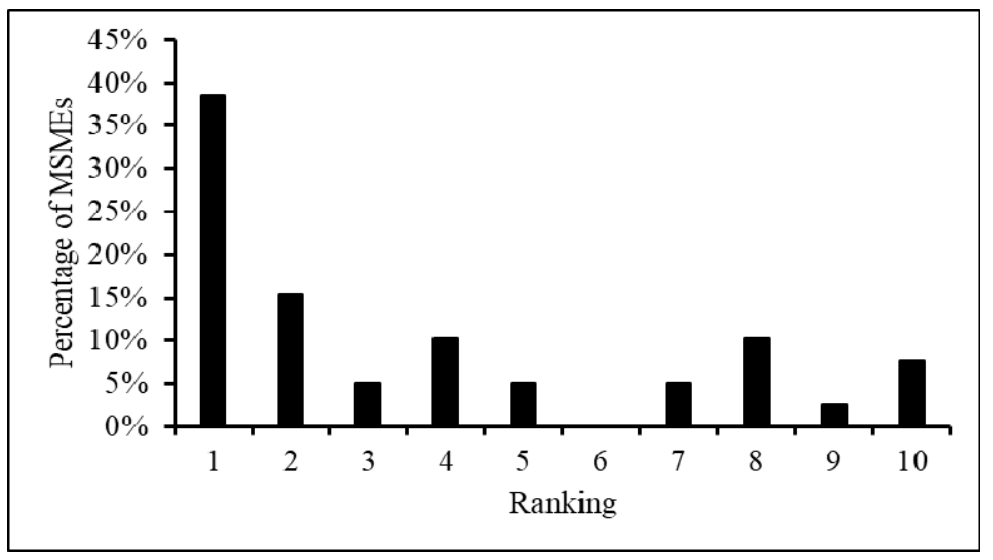

Figure 3. Adequacy of product assessment protocols in MSMEs on a scale of 1-10

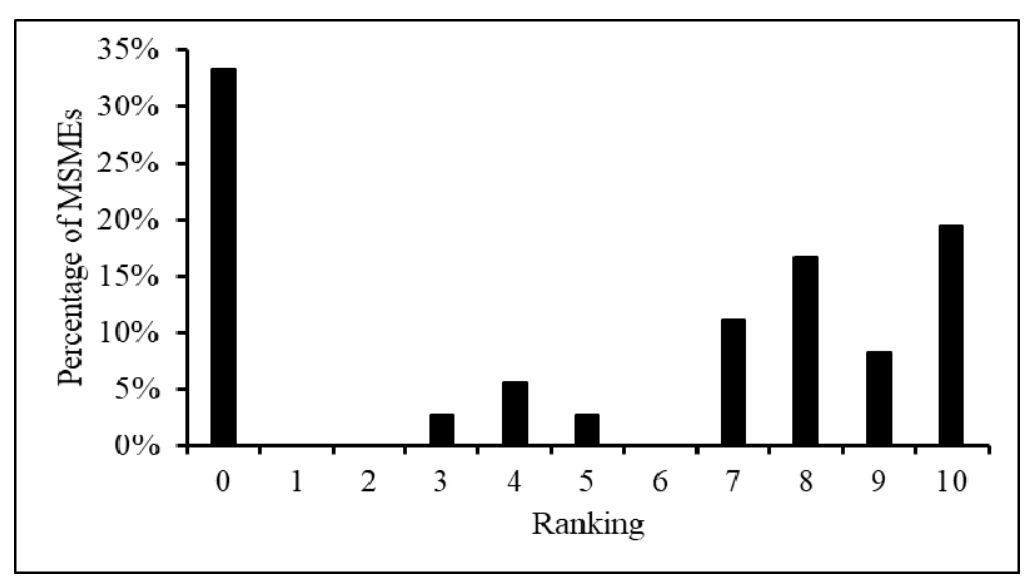

Figure 4. Adequacy of protocols for non-conforming utilized in MSMEs on scale of 0-10

The culture of keeping records for the finished products is very poor among processors following the low ranking (Figure 5). The finished products storage was slightly suitable for most processing facilities as shown in Figure 6. With regard to in-house testing of products, most of the tests at the MSMEs did not conform with the national standards as shown in Figure 7.

The ranking for appropriate product packaging was very high for most of the processing facilities (Figure 8, Table 9). However, the product labels generally used for most agro-processing MSMEs ranked low on a scale of 0-10 for adherence to UNBS standards for appropriate product packaging. About $12.1 \%$ of the agro-processing MSMEs had well designed labels that fully complied with UNBS standards (Figure 8). 
Table 9. Appropriateness of the packaging material for the food packaging

\begin{tabular}{llll}
\hline Appropriateness of packaging material & Freq. & Percent & Valid proportion \\
\hline Not at all & 1 & $2.6 \%$ & $2.6 \%$ \\
Not adequate & 4 & $10.3 \%$ & $10.3 \%$ \\
Slightly suitable & 3 & $7.7 \%$ & $7.7 \%$ \\
Suitable & 9 & $23.1 \%$ & $23.1 \%$ \\
Suitable and adequate & 22 & $56.4 \%$ & $56.4 \%$ \\
Total & 39 & $100 \%$ & $100 \%$ \\
Missing & 0 & 0.0 & \\
Total & 39 & $100.0 \%$ & \\
\hline
\end{tabular}

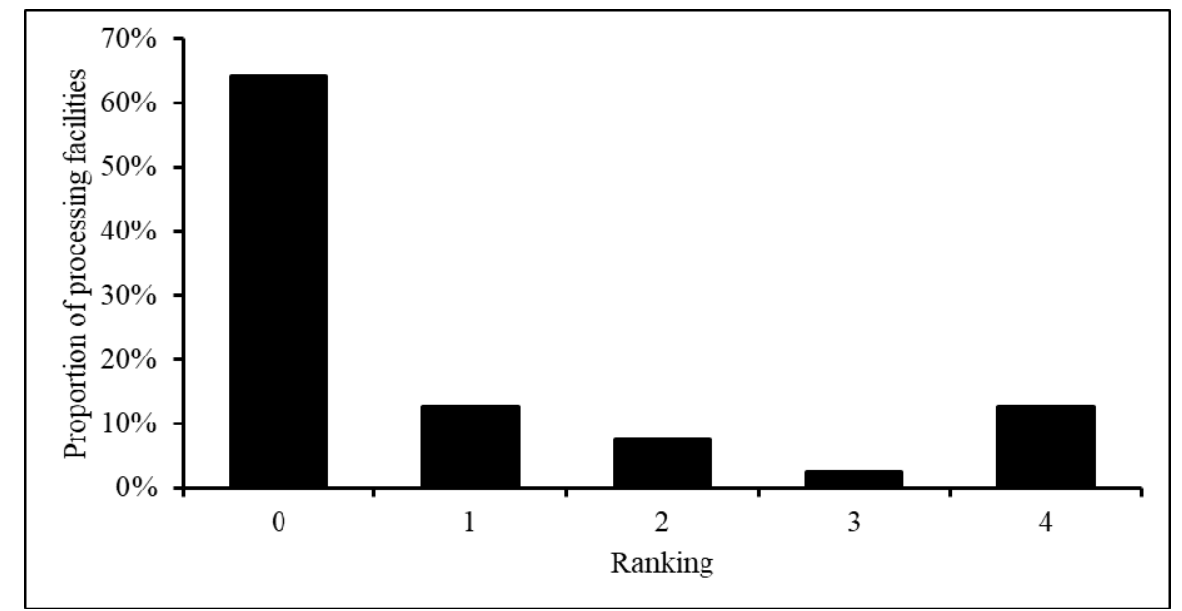

Figure 5. Extent of keeping records for finished products among the MSME processing facilities 


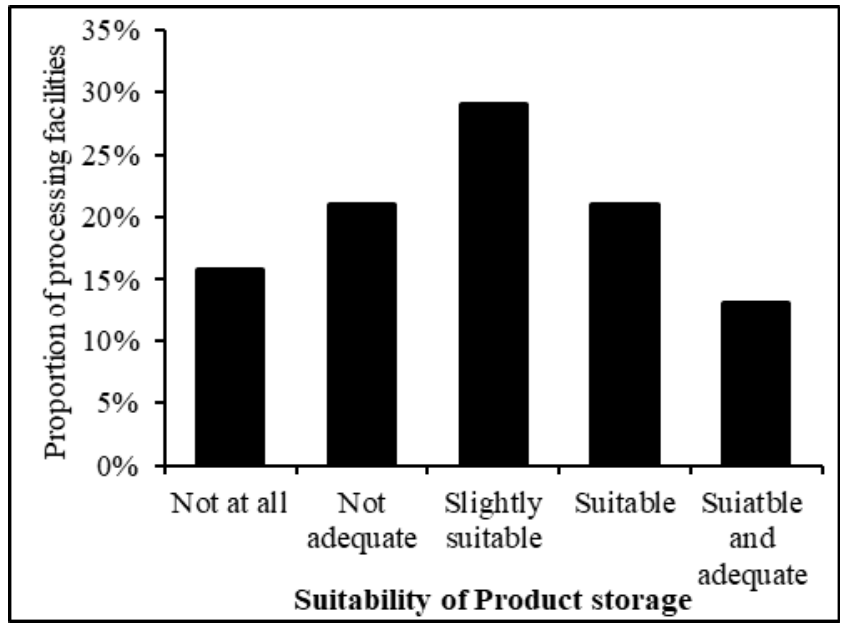

Figure 6. Suitability of finished product storage in MSMEs

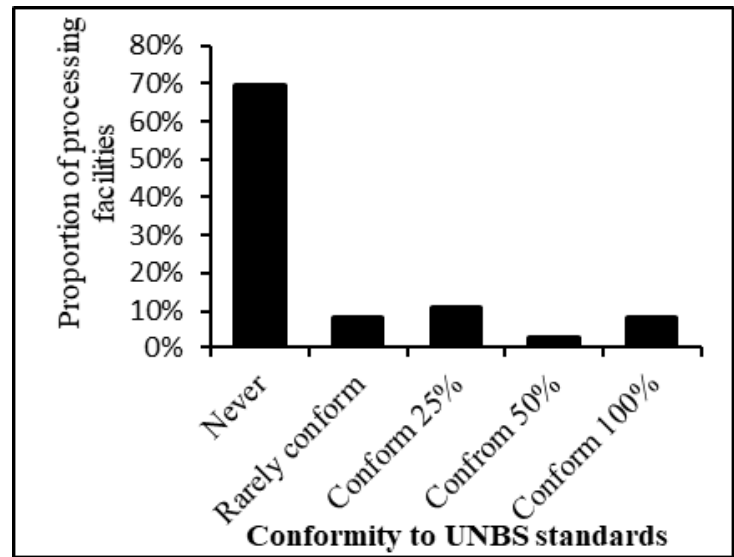

Figure 7. Conformity of in-house test results with national standards

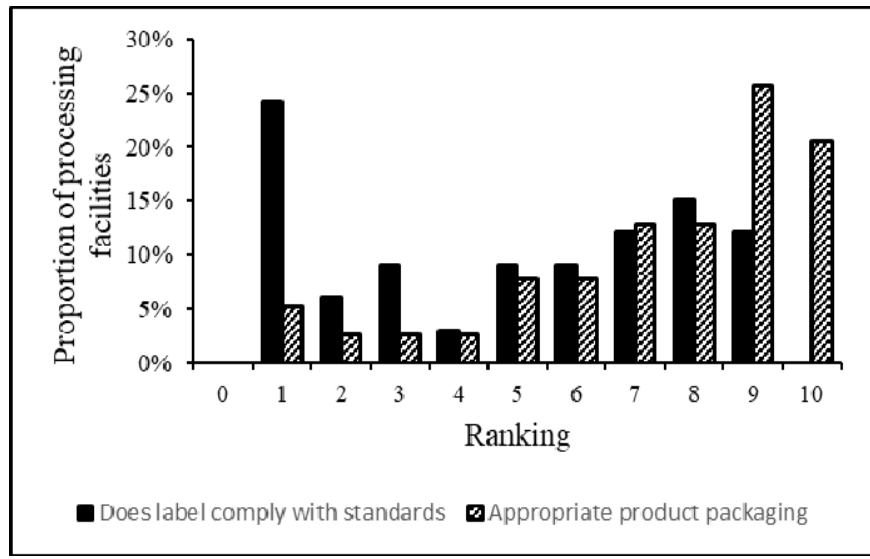

Figure 8. Proportion of processing facilities with labels that comply with standards and have appropriate product packaging 


\section{Macrothink}

\subsection{Waste Management and Pest Control}

The survey results indicated that $35.9 \%$ of the agro-processing MSMEs had very appropriate waste management strategies as shown (Table 10). However, only 5.1\% agro-processing MSMEs had their waste management plans documented. Results indicated that of 39 agro-processing MSMEs visited, 38.5\% ranked with 1 out of 10 (Figure 9) with respect to pest management. The small number of agro-processing MSMEs (7.7\%) had very appropriate pest management strategies. Some of the pest management methods used by the processors include rat traps, pest repellants, fumigation, and ultraviolet light.

Table 10. Waste management protocols at the MSME facilities

\begin{tabular}{llll}
\hline Appropriateness of waste management protocols & Freq. & Percent & Valid proportion \\
\hline Not at all & 4 & $10.3 \%$ & $10.3 \%$ \\
Not appropriate & 6 & $15.4 \%$ & $15.4 \%$ \\
Slightly appropriate & 12 & $30.8 \%$ & $30.8 \%$ \\
Appropriate & 14 & $35.9 \%$ & $35.9 \%$ \\
Very appropriate & 3 & $7.7 \%$ & $7.7 \%$ \\
Total & 39 & $100 \%$ & $100 \%$ \\
Missing & 0 & $0.0 \%$ & \\
Total & 39 & $100.0 \%$ & \\
\hline
\end{tabular}

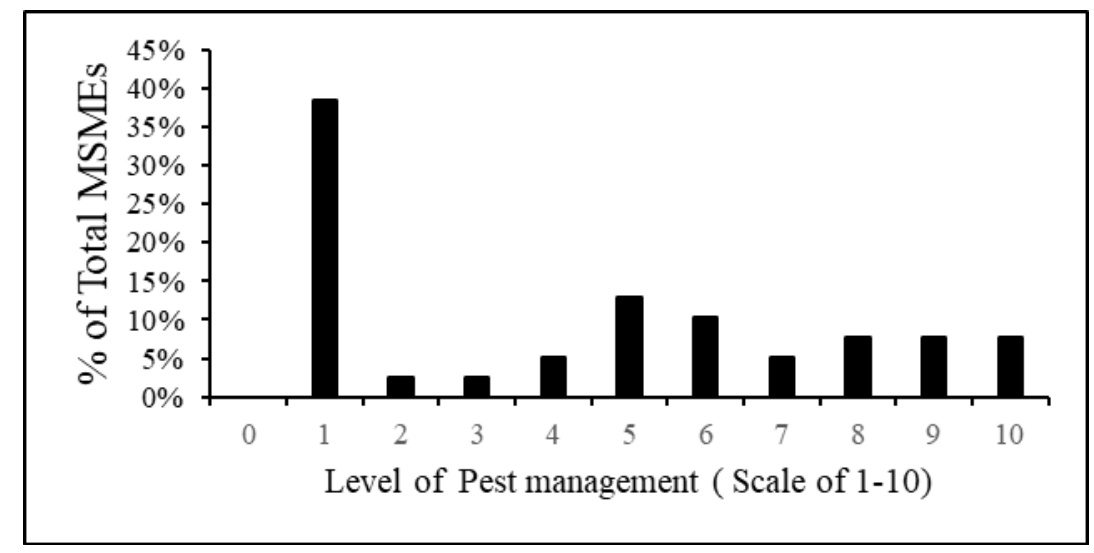

Figure 9. Extent to which pest management is done at the MSME facilities

\subsection{Infrastructure and Energy Utilization}

As shown in Figure 10, over 50\% of the agro-processing MSMEs did not have adequate 


\section{Macrothink}

facilities for production. Also, 61.5\% of the agro-processing MSMEs visited were not efficiently organized (Figure 10). However, 66.7\% of the agro-processing MSMEs were hygienically designed (Figure 10). The limited size of the agro-processing MSMEs could explain the poor facility organization. Results from the survey also revealed that only $15.4 \%$ of agro-processing MSMEs had the adequate equipment for production (Figure 10).

Sources of energy used by the processors during production included hydro power, solar, biomass (charcoal and firewood), biogas and others (Table 11). However, $74.4 \%$ of the agro-processing MSMEs do not maintain records of the energy used. Upon examining the extent to which the energy is efficiently utilized, it was found that over $30 \%$ of the agro-processing MSMEs generally efficiently utilized their energy (Table 12).

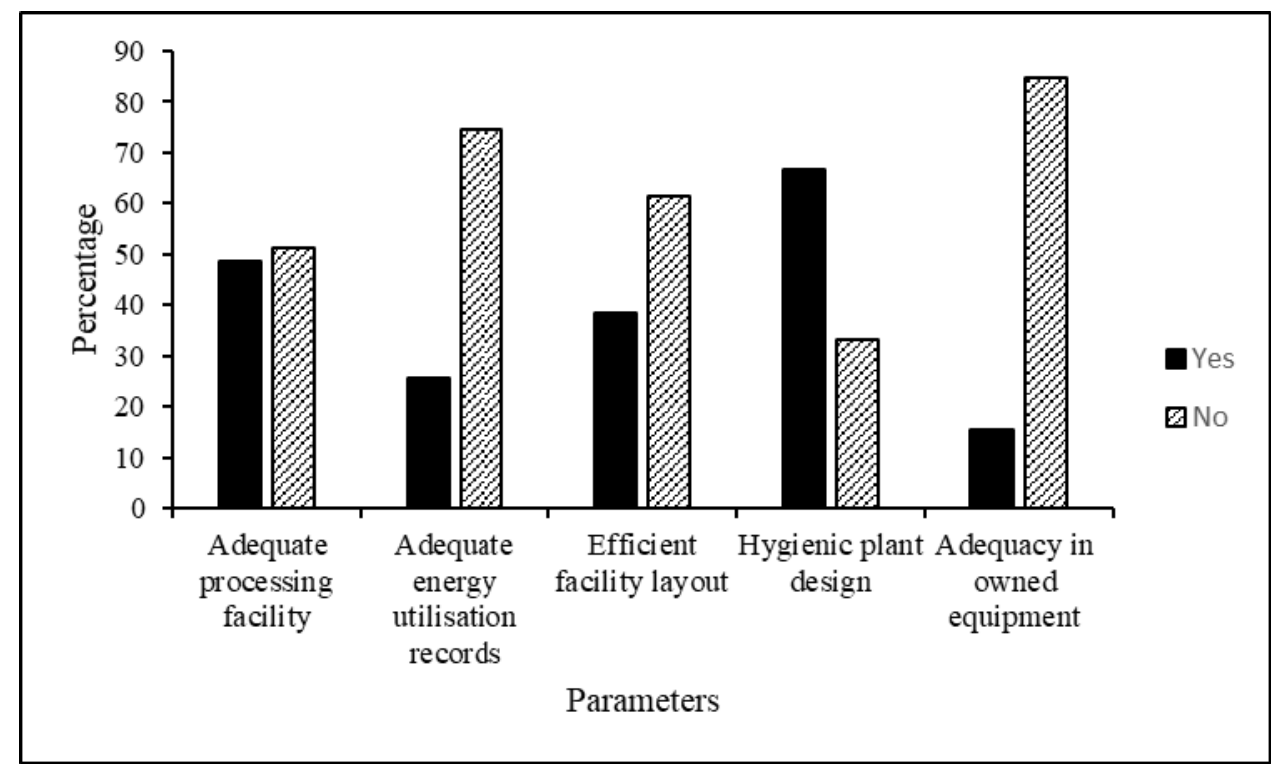

Figure 10. Proportion of facilities with (a) Adequate processing facility, (b) Adequate energy utilization records, (c) Efficient facility lay out, (d) Hygienic plant design, and (e) Adequacy in owned equipment 
Table 11. Types of energy utilized for production by selected agro-processing MSMEs

\begin{tabular}{llll}
\hline Energy source & Freq. & Percent & Percent of cases $(\mathrm{n}=39)$ \\
\hline Hydro Power & 31 & $58.5 \%$ & $79.5 \%$ \\
Solar Power & 10 & $18.9 \%$ & $25.6 \%$ \\
Biomass & 7 & $13.2 \%$ & $17.9 \%$ \\
Biogas & 1 & $1.9 \%$ & $2.6 \%$ \\
Other & 4 & $7.5 \%$ & $10.3 \%$ \\
Total & 53 & $100.0 \%$ & \\
\hline
\end{tabular}

Table 11. Extent to which energy is efficiently utilized

\begin{tabular}{llll}
\hline Extent of energy utilization & Freq. & Percent & Valid proportion \\
\hline Not at all & 1 & $2.6 \%$ & $2.6 \%$ \\
Slightly & 5 & $12.8 \%$ & $12.8 \%$ \\
Moderately & 11 & $28.2 \%$ & $28.2 \%$ \\
Somewhat efficient & 13 & $33.3 \%$ & $33.3 \%$ \\
Very efficient & 9 & $23.1 \%$ & $23.1 \%$ \\
Total & 39 & $100 \%$ & $100 \%$ \\
Missing & 0 & $0.0 \%$ & \\
Total & 39 & $100.0 \%$ & \\
\hline
\end{tabular}

\section{Discussion}

According to Gürbüz (2018), producers need to have adequate information on the consumer needs and regulatory requirements to produce a safe and profitable product. Product standards help producers access the necessary regulatory information in a simple and less-costly manner (Maur \& Shepherd, 2011). The absence of product standards among agro-processing MSMEs has serious implications on the level of understanding of standards. The fact that many agro-processing MSMEs have no access to requisite standards means that agro-processors are deprived of elementary understanding of the standards. This is evidenced by the $39.5 \%$ of facilities where standards are not understood at all. Knowledge from the food standards enables processors to optimize the sensory, nutritional, textural, packaging and cost of products. As such it was noted not much optimization was done in the facilities with reference to the regulatory standards. 


\section{MInstitute ${ }^{\text {Mink }}$}

Sensory (appearance, aroma, and flavor), and textual optimization should both based on sensory analysis and evaluation criteria. Sensory evaluation is based on the reactions of people/consumers to products as perceived by the senses (Stone, 2018). Though not formally done, in the processing facilitates it was noted that the feedback obtained from clients that use the products was used in the optimization of all sensory properties of their products.

The high percentage for optimization of product packaging in the processing facilities is not surprising, as the market provides a variety of appropriate product packaging material and at relatively low cost. On the other hand, the relatively low level of optimization for food nutritional aspects is attributed to lack of standards, limited understanding of standards, and technical knowledge in food product analysis. Many of the agro-processing MSMEs in Uganda are operated by non-food product development specialists (Adeyeye, 2017; Baluka et al., 2015). The inadequate declaration of raw materials and ingredients used in product development is influenced by lack of standards as well as limited understanding for those that have the standards. The detailed description of a good product label is well stipulated in the UNBS product standards as well as the labelling standard. The labels are often designed by highly qualified computer experts but with no training in food and the related regulations. This partially promotes the use of non-conforming product labels among the agro-processing MSMEs.

Good manufacturing Practices (GMPs) comprise of operations and environmental conditions provided by food handlers with the aim of producing of safe food products (Dias et al., 2012; Dudeja \& Singh, 2016; Kamboj et al., 2020). GMPs focus on personnel practices (personal hygiene, hand washing, clothing), raw materials, ingredients, and product handling; waste management, pest control, equipment maintenance, and conditions of the food processing premises (Dias et al., 2012; Kamboj et al., 2020). According to Tutu \& Anfu (2019), supply quality assurance, availability of well documented cleaning protocols, waste and pest management strategies, production control protocols, and personnel management are just enough to ensure food safety in small-scale food industries. However, the case of Uganda's agro-processing MSMEs seems to take a whole different trajectory. Results indicate that over $50 \%$ of the facilities do not have suitable raw material storage. Only $7.7 \%$ of the facilities have very clear process controls. About $38 \%$ of the agro-processing MSMEs ranked with 1 out of 10 for proper product assessment protocols. Over 30\% of the agro-processing MSMEs scored 0 out of 10 for proper identification of non-conforming products. Pest management was generally poor based on the majority rank of 1 out of 10 . Only $7.7 \%$ of the agro-processing MSMEs had very appropriate waste management systems. The result, therefore, jeopardizes product safety, and as well delay the product certification processes. Only $38.5 \%$ had an efficiently organized facility layout. This could be attributed to inadequate facility planning and finances for investment. A study by Ojaghi et al. (2015) revealed that proper facility planning and layout not only ensures sustainable processes but also reduces losses along the production line. Also, efficient facility layout improves productivity as it reduces the overall processing lead time and labor efficiency (Naqvi et al., 2016).

Well maintained records provide evidence for conformance of the food facilities with the 
different food regulations including good manufacturing procedures (GMPs). Results indicated that record keeping for the agro-processing MSMEs is generally poor across the board. These findings agreed with the study done by Myeko \& Madikane (2019) in South Africa, which indicated that majority of the participating small, micro, medium enterprises did not practice proper record keeping. This could be due to the limited information on the good manufacturing practices since many of the processors are self-developed food processors with almost no formal food handling training.

Despite the huge implication of export trade on the firms' profits (Atkin \& Jinhage, 2017), agro-processing MSMEs in Uganda continue to trail in this area. Factors such as financial capital (Paul et al., 2017) and product certification have a bearing on the extent of export trade for any product or company. According to Bangwayo-Skeete \& Moore (2015), product certification reduces the barriers related to perceptions of poor production techniques therefore, guaranteeing quality and safety for the end-users.

\section{Conclusions}

The operations at the agro-processing MSMEs in Uganda generally do not comply with the set food manufacturing standards, therefore, exposing the product end-user to food safety challenges. Many of the operations do not meet the requirements for product certification by UNBS, yet many agro-processing MSMEs mentioned it as a limiting factor for product marketing both locally and for export market. Inadequate documentation was a cross-cutting issues for all operations. The major issues with operations stem from a lack of formal training in food handling. There is, therefore, need to strengthen the knowledge and practice of regulatory food standards (UNBS) in the agro-processing MSMEs through continuous human and institutional-capacity development programs such as trainings and financial support for further investment into food handling systems, including though not limited to procurement of appropriate equipment.

\section{Conflict of Interest Statement}

The authors declare that they have no conflict of interest.

\section{Acknowledgments}

This work was supported by the Government of Uganda through Makerere University Research and Innovation Fund (RIF) [grant number RIF1/CAES/008]. Special thanks to the various agro-processing MSMEs in Uganda for supporting us in this study.

\section{References}

Abisuga-Oyekunle, O. A., Patra, S. K., \& Muchie, M. (2019). SMEs in sustainable development: Their role in poverty reduction and employment generation in sub-Saharan Africa. African Journal of Science, Technology, Innovation and Development, 12(4), 405-419. https://doi.org/10.1080/20421338.2019.1656428

Adeyeye, S. A. O. (2017). The role of food processing and appropriate storage technologies in ensuring food security and food availability in Africa. Nutrition \& Food Science, 47(1), 


\section{Macrothink}

122-139. https://doi.org/10.1108/NFS-03-2016-0037

Atkin, D., \& Jinhage, A. (2017). Trading up: The benefits of exporting for small firms (IGC, Growth Brief Series No. 11). London.

Baluka, S. A., Miller, R., \& Kaneene, J. B. (2015). Hygiene practices and food contamination in managed food service facilities in Uganda. African Journal of Food Science, 9(1), 31-42. https://doi.org/10.5897/AJFS2014.1170

Bangwayo-Skeete, P. F., \& Moore, W. R. (2015). ENTRY INTO EXPORT MARKETS AND QUALITY CERTIFICATIONS: EVIDENCE FROM DEVELOPING COUNTRIES. Applied Econometrics and International Development, 15(2), 17-34.

Dias, C. M. A., Sant'Ana, A. S., Cruz, A. G., Faria, J. d. A. F., Fernandes de Oliveira, C. A., \& Bona, E. (2012). On the implementation of good manufacturing practices in a small processing unity of mozzarella cheese in Brazil. Food Control, 24(1-2), 199-205. https://doi.org/10.1016/j.foodcont.2011.09.028

Dudeja, P., \& Singh, A. (2016). Good Manufacturing Practices. In P. Dudeja, A. Singh, \& S. Kaur (Eds.), Food safety Impelementation: from Farm to Fork (1st ed., pp. 130-145). India: CBS Publishers \& Distributors Pvt Ltd.

Erdin, C., \& Ozkaya, G. (2020). Contribution of small and medium enterprises to economic development and quality of life in Turkey. Heliyon, 6(2), e03215. https://doi.org/10.1016/j.heliyon.2020.e03215

Gherghina, Ș. C., Botezatu, M. A., Hosszu, A., \& Simionescu, L. N. (2020). Small and medium-sized enterprises (SMEs): The engine of economic growth through investments and innovation. Sustainability, 12(1), 347. https://doi.org/10.3390/su12010347

Gürbüz, E. (2018). Theory of new product development and its applications. Marketing (pp. 57-75). https://doi.org/10.5772/intechopen.74527

Hamiza, O. (2020). The Impact of Coronavirus Lockdown on Small Scale Businesses in Arua Municipality, Uganda. International Journal of Science and Research, 9(8), 1239-1248.

Kakembo, S. H., Abduh, M., \& Pg Hj Md Salleh, P. M. H. A. (2021). Adopting Islamic microfinance as a mechanism of financing small and medium enterprises in Uganda. Journal of Small Business and Enterprise Development, 28(4), 537-552. https://doi.org/10.1108/JSBED-04-2019-0126

Kamboj, S., Gupta, N., Bandral, J. D., Gandotra, G., \& Anjum, N. (2020). Food safety and hygiene: A review. International Journal of Chemical Studies, 8(2), 358-368. https://doi.org/10.22271/chemi.2020.v8.i2f.8794

Lakuma, C. P., Marty, R., \& Muhumuza, F. (2019). Financial inclusion and micro, small, and medium enterprises (MSMEs) growth in Uganda. Journal of Innovation and Entrepreneurship, 8(1), 1-20. https://doi.org/10.1186/s13731-019-0110-2

Maur, J.-C., \& Shepherd, B. (2011). Product Standards. In Preferential Trade Agreement 


\section{Macrothink}

Policies for Development (pp. 197-216). https://doi.org/10.1596/9780821386439_CH10

MTIC. (2015). Uganda Micro, Small And Medium Enterprise (MSME) Policy - Sustainable MSMEs for Wealth Creation and Socio-Economic Transformation. Retrieved from Kampala, Uganda:

https://www.ugandainvest.go.ug/wp-content/uploads/2016/02/Final-MSME-Policy-July-2015 .pdf

Myeko, Z., \& Madikane, V. (2019). Challenges of Record Keeping for Engcobo Small, Micro and Medium Businesses, South Africa. Global Journal of Management and Business Research: (B), 19(3).

Naqvi, A. S. A., Fahad, M., Atir, M., Zubair, M., \& Shehzad, M. M. (2016). Productivity improvement of a manufacturing facility using systematic layout planning. Cogent Engineering, 3(1). https://doi.org/10.1080/23311916.2016.1207296

Ojaghi, Y., Khademi, A., Yusof, N. M., Renani, N. G., \& bin Syed Hassan, S. A. H. (2015). Production Layout Optimization for Small and Medium Scale Food Industry. Procedia CIRP, 26, 247-251. https://doi.org/10.1016/j.procir.2014.07.050

Paul, J., Parthasarathy, S., \& Gupta, P. (2017). Exporting challenges of SMEs: A review and future research agenda. Journal of World Business, 52(3), 327-342. https://doi.org/10.1016/j.jwb.2017.01.003

Quartey, P., Turkson, E., Abor, J. Y., \& Iddrisu, A. M. (2017). Financing the growth of SMEs in Africa: What are the contraints to SME financing within ECOWAS? Review of Development Finance, 7(1), 18-28. https://doi.org/10.1016/j.rdf.2017.03.001

Shafi, M., Liu, J., \& Ren, W. (2020). Impact of COVID-19 pandemic on micro, small, and medium-sized Enterprises operating in Pakistan. Research in Globalization, 2, 100018. https://doi.org/10.1016/j.resglo.2020.100018

Stone, H. (2018). Example food: What are its sensory properties and why is that important? NPJ Science of Food, 2(1), 1-3. https://doi.org/10.1038/s41538-018-0019-3

Tutu, B. O., \& Anfu, P. O. (2019). Evaluation of the food safety and quality management systems of the cottage food manufacturing industry in Ghana. Food control, 101, 24-28. https://doi.org/10.1016/j.foodcont.2019.02.028

UNBS. (2018). The "Q" Mark is the only Distinctive Mark given by UNBS. Quality Chronicles, 46.

UNBS. (2019). Policy on Certification Fees. Retrieved from Kampala, Uganda: https://www.unbs.go.ug/attachments/menus/45/CERT-POL- 01 Policy on Certification Fees.pdf 
Appendix

\section{BASELINE EVALUATION FORM \\ FOR AGRO-PROCESSING MSMES PARTICIPATING IN MAKERERE UNIVERSITY EAPI PROJECT}

Date:

\section{Introduction, Purpose, Confidentiality, and Consent clause}

Introduction \& Purpose: My name is ............................ I am part of the EAPI Project team supporting the agro-processing MSMEs for product certification. The purpose of this survey is to establish the baseline information which will act as a reference point to measure and compare your company's progress towards product certification by the UNBS. This information will also support both the EAPI project team and the agro-processing MSMEs staff to develop appropriate interventions to fast track the product certification process.

Confidentiality Statement: The information obtained through this survey and any files transmitted within shall remain confidential and only used for the intended purpose. Except for the EAPI project team, funding agency, and the participant, no third parties shall have access to the information gathered through this survey.

Voluntary participation: Your participation is entirely voluntary. You also do not have to answer any question that makes you uncomfortable.

Do you consent to participate in this survey? (Tick) $\square$ Yes

Photography: As part of the information gathering, it may deem relevant for the EAPI team to take photos.

(i) Do you consent to that the EAPI Project team takes photographs? (Tick) $\square$ Yes $\square$ No

(ii) Do you grant full rights to use the images resulting from the photographs, and any reproductions adaptations of images for report making and any other project relation publications? (Tick) $\square$ Yes

$\square$ No

Name of Participant:

Signature:

Name of the

MSME:

Location of MSMEs:

Name of the Interviewer:

Signature: 


\section{Section 1: Product Optimization}

1.1 Name of Product(s) and brand(s):

1.2 Does the company have relevant standards (s)? (Please confirm) $\square$ Yes

1.3 If yes in 2.1, list the available standard(s) (Use standards codes)

1.4 To what extent do you understand the standards? (tick)

$\square$ Not at all $\square$ Slightly understood $\square$ Understood $\square$ Very clearly understood

1.5 To what extent is product optimization done? (tick) Note: Consider product texture, sensory acceptability, nutritional properties, and packaging for product optimization

$\square$ No parameter optimized $\square$ One aspect optimized $\square \quad$ Two aspects $\quad$ optimized $\square$ Three aspects optimized $\square$ All aspect optimized

1.6 What parameters have been optimized? (Tick all applicable)

$\square$ Textural $\square$ Sensory $\square$ Nutritional $\square$ Packaging

\section{Section 2: Raw material verification, storage and product labelling}

2.1 Which raw materials and/ or additives are used in your product?

2.2 Are the identified raw materials confirmed the same as those declared on the product label (as applicable)? $\square$ Yes

$\square$ No

2.3 To what extent are the records maintained for the incoming raw materials in your company?

$\square$ Never $\square$ Once in a while $\square$ Twice a week $\square$ Thrice a week $\square$ Always maintained

2.4 Assess the suitability of raw materials storage at the facility?

$\square$ Not suitable at all $\square$ Slightly suitable with several gaps $\square$ Moderately suitable with few gaps $\square$ Suitable $\square$ Very suitable

\section{Section 3: Good Manufacturing Practices (GMPs)}

3.1 List the cleaning materials and tools used in the processing facility 
3.2 Are the cleaning materials and tools properly identified and separated? Yes No

3.3 Do you have an established routine for cleaning both equipment and premise? Yes No

3.4 On a scale of $0-10$, rate the extent to which floors, windows, walls, and celling are maintained clean? ( 0 - Not maintained at all, 10 - Extremely maintained clean $)$
0 1
$2 \quad 3$
4
5
6
$7 \quad 8$
9
10

3.5 On a scale of $0-10$, rate the extent to which the facility has an established routine for cleaning equipment and premises? $(0$ - No established routine, 10 - Well documented routine)

$\begin{array}{lllllllllll}0 & 1 & 2 & 3 & 4 & 5 & 6 & 7 & 8 & 9 & 10\end{array}$

3.5 On a scale of $0-10$, rate the extent to the following personal hygiene parameters are handled at the processing facility? (Tick were applicable)

\begin{tabular}{|c|c|c|c|c|c|c|c|c|c|c|c|}
\hline Parameter & 0 & 1 & 2 & 3 & 4 & 5 & 6 & 7 & 8 & 9 & 10 \\
\hline $\begin{array}{l}\text { Valid medical certificate maintained (0-Not } \\
\text { at all maintained, } 10 \text {-Well maintained) }\end{array}$ & & & & & & & & & & & \\
\hline $\begin{array}{l}\text { Personnel routinely inspected }\left(0-\mathrm{No}_{\mathrm{O}}\right. \\
\text { inspection, } 10 \text {-Well documented routine })\end{array}$ & & & & & & & & & & & \\
\hline $\begin{array}{l}\text { Appropriate protective gear provided }(0-\mathrm{No} \\
\text { PPEs provided, } 10 \text {-Very clean protective gear } \\
\text { available) }\end{array}$ & & & & & & & & & & & \\
\hline $\begin{array}{l}\text { Toilet facilities provided and maintained } \\
(0 \text {-Not provided, not maintained, } \\
\text { 10-Provided and maintained) }\end{array}$ & & & & & & & & & & & \\
\hline
\end{tabular}

3.6 Was the company in production on the day of the audit? Yes

No

3.7 Briefly outline the key production steps (Sketch the process flow chart on a separate sheet of paper) 


\section{Macrothink}

3.8 Does the processing facility have clear production process controls in place?

None $\square$ Yes with a lot of gaps $\square$ Yes with a few gaps $\square$ yes with slightly clear process controls $\square$ Yes with very clear process controls

3.9 To what extent are records maintained for production process controls?

Never $\square$ Once in a while $\square$ Twice a week $\square$ Thrice a week $\square \quad$ Always maintained

\section{Section 4: Measuring and Testing equipment}

4.1 What is the extent of the facility's possession and calibration of measuring and testing equipment?
None
Neither adequate nor calibrated
Adequate and calibrated

4.2 What measuring and testing equipment is available at the facility?

4.3 Who does the calibration of your equipment?

\section{Section 5: Product assessment, presentation, and storage}

5.1 On a scale of 1-10, rate the adequacy of product assessment protocols carried out at the MSMEs? (1 - No product assessment, 10 - Adequate product assessment protocols)

$\begin{array}{llllllllll}1 & 2 & 3 & 4 & 5 & 6 & 7 & 8 & 9 & 10\end{array}$

5.2 On a scale of 0-10, rate the adequacy of protocols for non-conforming products utilized at the MSMEs? ( 0 - No protocol for identification of non-conforming products, 10 - Adequate protocol)

$\begin{array}{lllllllllll}0 & 1 & 2 & 3 & 4 & 5 & 6 & 7 & 8 & 9 & 10\end{array}$

5.3 How are the non-conforming products handled?

5.3 Identify whether the test results from in-house analysis of product conform to the national standards. 
$\square$ Never $\square$ Rarely conform $\square$ Conform $25 \% \quad \square$ Conform $50 \%$ Conform $100 \%$

5.4 On a scale of $0-4$, rate the extent to which records relating to the finished product are maintained at the facility?

$\begin{array}{lllll}0 & 1 & 2 & 3 & 4\end{array}$

5.5 Assess the adequacy and suitability of the finished product storage at the facility?

Not at all $\square$ Not adequate $\square$ Slightly suitable $\square$ Suitable $\square \quad$ Suitable and adequate

5.6 On a scale of $0-10$, rate the compliancy of the product label and marks with the requirements of relevant standards. $(0-$ Not compliant, 10 - Completely compliant $)$

$\begin{array}{lllllllllll}0 & 1 & 2 & 3 & 4 & 5 & 6 & 7 & 8 & 9 & 10\end{array}$

5.7 On a scale of $0-10$, rate the appropriateness of packaging material for the product packaging? (0 - Not appropriate, 10 - Very appropriate)

$\begin{array}{lllllllllll}0 & 1 & 2 & 3 & 4 & 5 & 6 & 7 & 8 & 9 & 10\end{array}$

5.8 Is the product packaging appropriate for the intended use e.g., food grade material for food products, and proper storage and handling?

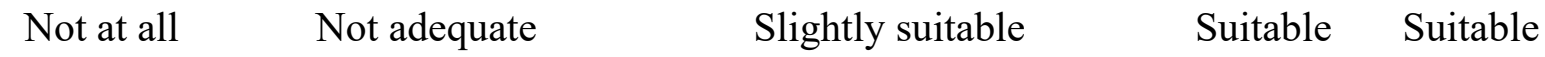
and adequate

\section{Section 6: Waste management and Pest Control}

6.1 Does the company have an appropriate waste management system?

Not at all Not appropriate Slightly appropriate Appropriate

Very appropriate

6.2 Does the company have a documented waste management plan? Yes No

6.3 On a scale of $0-10$, rate the extent to which pest management is done at the facility? $(0-$ Not at all, 10 - Very appropriate pest management strategy)

$\begin{array}{lllllllllll}0 & 1 & 2 & 3 & 4 & 5 & 6 & 7 & 8 & 9 & 10\end{array}$

6.4 Identify the pest management methods used at the facility 


\section{Section 7: Infrastructure and energy utilization}

7.1 Is the size of the facility adequate for production? Yes No

7.2 Is the facility layout efficient organized for production? Yes No

7.3 Is the facility design hygienic for production? Yes No

7.4 Does the facility have adequate equipment? Yes No

7.5 What energy sources are utilized at this facility?
Hydro power
Solar power
Biomass
Biogas
Others

7.6 To what extent is the energy efficiently utilized at the facility?

Not at all

Slightly

Moderately

Somewhat efficient

Very efficient

\section{Thank you}

\section{Copyright Disclaimer}

Copyright for this article is retained by the author(s), with first publication rights granted to the journal.

This is an open-access article distributed under the terms and conditions of the Creative Commons Attribution license (http://creativecommons.org/licenses/by/4.0/). 